Thabiea : Journal of Natural Science Teaching
Program Studi Tadris Ilmu Pengetahuan Alam
Institut Agama Islam Negeri Kudus
http://journal.stainkudus.ac.id/index.php/Thabiea
$p$-issn: 25808474

\title{
Analisis Argumentasi dalam Isu Sosiosaintifik Siswa SMP
}

\author{
Deni Fauzi Rahman a,1 \\ a Departemen Pendidikan IPA Pasca Sarjana, Universitas Pendidikan Indonesia, Jl. Dr. Setiabudi No. 229, Bandung 40154, \\ Indonesia \\ ${ }^{1}$ denidefan@gmail.com
}

\begin{tabular}{ll}
\hline Kata Kunci & ABSTRAK \\
\hline Kompetensi Abad 21 & Pendidikan abad ke 21 berfokus pada peningkatan kompetensi kreatif, \\
Argumentasi & berpikir kritis, kerja sama, dan komunikasi. Berdasarkan hal tersebut, \\
Isu Sosiosaintifik & argumentasi dapat menjadi salah satu solusi untuk untuk menjawab \\
& tantangan dikarenakan dapat memfasilitasi kompetensi berfikir kritis dan \\
& komunikasi. Argumentasi dapat digunakan dalam isu sosiosaintifik yang \\
& menyajikan permasalahan secara terbuka dan dapat didebat. Metode \\
penelitian ini adalah deskriptif kualitatif. Penelitian ini bertujuan untuk & mengetahui kualitas argumentasi pada isu sosiosaintifik melalui tema \\
plastik topik pencemaran. Analisis argumentasi menggunakan komponen & TAP (Toulmin's Argument Pattern) yang terdiri dari 6 komponen yaitu \\
& claims, data, warrant, backing, qualifier, dan rebuttals. Berdasarkan hasil \\
penelitian diperoleh bahwa kualitas argumentasi dalam isu sosiosaintifik & siswa SMP masih rendah. Rendahnya kualitas argumentasi disebabkan \\
& oleh rendahnya pemahaman konsep siswa. \\
& ABStRACT
\end{tabular}

\begin{tabular}{ll}
\hline Key Words & ABSTRACT \\
\hline $21^{\text {st }}$ Century Competencies & Analysis of Argumentation in Socio-Scientific Issues of junior High \\
Argumentation & School Students. The 21 st Century Education focuses on the \\
Socio-scientific issues & development of the competence in creativity, critical-thinking, \\
& communication, and collaboration. Based on that reason, the \\
& argumentation can be one of the solutions to answer this issue since it \\
& facilitates the critical-thinking and communication competences. \\
& Arguments can be used in socio-scientific issues that present open \\
& problems and debatable. The metod of research is descriptive qualitative. \\
& The aims of research is to find out the quality of the argumentation on the \\
& socio-scientific issue through the plastic theme of the topic of pollution. \\
& Argumentation analysis using TAP (Toulmin's Argument Pattern) \\
consisting of 6 components, namely claims, data, warrant, backing, & qualifier, and rebuttals. Based on the results of the research, it was found \\
that the quality of the argumentation in the socio-scientific issues of & junior high school students was still low. The low quality of \\
argumentation is caused by the poor of students' concept understanding.
\end{tabular}

Copyright (C) 2018 Institut Agama Islam Negeri Kudus. All Right Reserved

\section{Pendahuluan}

Pendidikan abad ke 21 berfokus pada peningkatan kompetensi kreatif, berfikir kritis, kerja sama, dan komunikasi (Partnership for $21^{\text {st }}$ Century Learning, 2015). Empat kompetensi tersebut dikenal dengan nama $4 \mathrm{C}$ (Creativity, Critical Thinking, Collaboration, and Communication). Hal ini menjadi tantangan untuk dunia pendidikan khususnya sekolah untuk menemukan cara bagaimana empat kompetensi tersebut dapat dimiliki oleh siswa.

Di Indonesia, tantangan kompetensi abad ke 21 dijawab melalui Permendikbud No. 22 tahun 2016 revisi yang mewajibkan 4C sebagai kompetensi yang wajib dikembangkan dalam pembelajaran. Teknis pelaksanaannya adalah dengan mengintegrasikan $4 \mathrm{C}$ bersama dengan Penguatan Pendidikan Karakter (PPK) dan literasi dalam Rencana Pelaksanaan Pembelajaran (RPP). Dengan pengintegrasian 
tersebut diharapkan kompetensi 4C dapat dimiliki oleh siswa.

Dalam pembelajarannya, argumentasi dapat menjadi salah satu sarana untuk meningkatkan kompetensi abad 21. Argumentasi dapat memfasilitasi beberapa kompetensi abad 21, diantaranya adalah kompetensi berfikir kritis (Hall, 2011; Inch, 2006; Makhene, 2017; Sanders, 1994). Selain itu, argumentasi juga dapat mengembangkan kompetensi komunikasi (Hall, 2011; Inch 2006). Selain itu, argumentasi juga memiliki beberapa alasan penting untuk diterapkan dalam pembelajaran IPA yaitu: (1) ilmuwan menggunakan argumentasi dalam mengembangkan dan meningkatkan pengetahuan ilmiahnya; (2) masyarakat menggunakan argumetasi dalam perdebatan ilmiah; dan (3) peserta didik dalam pembelajaran membutuhkan argumentasi utnuk memperkuat pemahamannya (Erduran et al., 2004).

Argumentasi merupakan proses memperkuat suatu klaim melalui analisis berpikir kritis berdasarkan dukungan bukti dan alasan yang logis. Bukti dan alasan tersebut mengandung fakta atau kondisi objektif yang dapat diterima sebagai suatu kebenaran (Inch, 2006). Sampson dan Clark (2006) menyatakan setidaknya ada 5 framework yang digunakan untuk penilaian argumentasi. Framework tersebut antara lain:

1. Toulmin's Argument Pattern digunakan dalam penelitian pendidikan IPA (Erduran et al., 2004; Jimenez-Aleixandre et al., 2000; Kelly et al., 1998).

2. Zohar and Nemet's framework merupakan modifikasi dari Toulmin (Zohar dan Nemet, 2002).

3. Kelly and Takao's framework tentang status epistemik argumen (Kelly \& Takao, 2002; Takao \& Kelly, 2003).

4. Sandoval's framework digunakan untuk kualitas konsep dan epistemik argumen (Sandoval, 2003; Sandoval \& Millwood, 2005).
5. Lawson framework digunakan untuk validitas deduktif argumen (Lawson, 2003). Argumentasi berdasarkan Toulmin (Toulmin's Argument Pattern) memiliki enam komponen utama yaitu: (1) claims, terdiri dari penyampaian pendapat atau kesimpulan yang akan diterima oleh orang lain; (2) data, fakta atau sebuah kondisi yang secara objektif dapat diobservasi, dipercaya, dan diterima secara jelas; (3) warrants, penjelasan dari hubungan antara data dengan claims; (4) backing yaitu asumsi dasar yang mendukung warrants; (5) qualifiers yaitu memberi bukti spesifik yang menyatakan bahwa claims yang dinyatakan adalah benar; dan (6) rebuttals, pernyataan yang menyanggah atau menentang (Inch, 2006).

Kemampuan argumentasi dapat membekali siswa untuk memberikan penjelasan terhadap fenomena di bidang ilmiah yang terjadi dalam kehidupan sehari-hari (Osborne, 2010). Fenomena tersebut tidak terlepas dari masalah sosial. Sarana untuk menjelaskan masalah sosial yang terjadi di bidang ilmiah telah dikenalkan sebagai isu sosiosaintifik (Gayford, 2002; Kolsto, 2001; Sadler, 2004; Sadler \& Zeidler, 2004; Sadler et al., 2004; Zeidler et al., 2002). Menurut Sadler (2004) dalam isu sosiosaintifik masalah yang disajikan memiliki karakter kompleks, terbuka, tidak terstruktur, dan dapat didebat.

Pengembangan argumentasi dalam isu sosiosaintifik memiki tantangan tersendiri. Di satu sisi masalah yang disajikan harus memberikan peluang untuk pandangan yang berbeda. Di sisi lainnya siswa harus memiliki pengetahuan yang luas dari berbagai disiplin ilmu. Sadler \& Donnely (2006) mengembangkan rubrik yang menilai argumentasi dalam isu sosiosaintifk. Kriteria yang pertama adalah claims atau rebuttals harus dapat memberikan dasar (data, warrants, atau backing) yang meyakinkan sehingga orang lain dapat mengikutinya. Kriteria yang kedua adalah claims atau rebuttals harus diikuti oleh dasar (data, warrants, atau backing) yang benar, logis, dan konsisten. Kriteria yang ketiga adalah 
multi perspektif yaitu penilaian yang dilakukan jika siswa dapat memberikan perspektif yang berbeda. Sejalan dengan Toulmin, Erduran (2004) memberikan gambaran bahwa penilaian dapat dilakukan jika claims atau rebuttals yang disampaikan siswa diikuti oleh dasar (data, warrants, atau backing).

Penelitian ini bertujuan untuk mengetahui kualitas argumentasi pada isu sosiosaintifik melalui tema plastik topik pencemaran. Tema plastik dipilih dikarenakan dekat dengan siswa dan menjadi permasalahan riil dalam kehidupan sehari-hari. Permasalahan riil dan konstektual akan lebih mudah dipahami oleh siswa (Lang \& Olson, 2000).

\section{Metode}

Penelitian ini dilakukan di kelas VII Sekolah Menengah Pertama (SMP). Siswa yang terlibat berjumlah 31 orang. Penelitian dilakukan ketika pembelajaran topik pencemaran yang terkait dengan Kompetensi Dasar 3.8 Menganalisis terjadinya pencemaran lingkungan dan dampaknya bagi ekosistem. Permasalahan isu sosiosaintifik mengenai pencemaran diberikan sebagai evaluasi pembelajaran topik pencemaran.

Instrumen yang digunakan berupa soal essay tertulis. Jawaban dari soal essay dianalisis menggunakan komponen TAP (Toulmin's Argument Pattern) yang terdiri dari 6 komponen. Dari instrumen tersebut diperoleh data kualitatif argumentasi tertulis.

\section{Hasil dan pembahasan}

Berdasarkan hasil penelitian, diperoleh data jawaban siswa mengenai permasalahan isu sosiosaintifik tentang plastik. Permasalahan yang disajikan memiliki karakter terbuka dan dapat didebat. Gambar 1 menunjukkan contoh permasalahan isu sosiosaintifik tentang plastik yang harus dijawab oleh siswa.
Warga Kelurahan Pagarsih dihadapkan pada masalah sampah plastik yang terus menggunung. Sampah tersebut mengeluarkan bau yang tak sedap sehingga berbahaya untuk kesehatan. Akhirnya mereka berbondong-bondong mengubur sampah plastik di halaman rumah mereka.

a. Menurut pendapatmu, apakah yang dilakukan oleh warga sudah tepat?

b. Mengapa tindakan tersebut tepat / tidak tepat?

Gambar 1. Contoh Permasalahan Isu Sosiosaintifik Plastik

Jawaban yang disajikan oleh siswa dikelompokkan sesuai dengan komponen argumentasi Toulmin. Pernyataan "tepat" pada poin a merupakan claims dan pernyataan "tidak tepat" merupakan rebuttals atas permasalahan tersebut. Pada poin $\mathrm{b}$, alasan mengandung dasar, dapat berupa data, warrant, dan backing. Contoh pengelompokkan jawaban siswa dapat dilihat pada tabel 1 .

Tabel 1. Contoh Pengelompokkan Jawaban

\begin{tabular}{lcl}
\hline \multirow{2}{*}{\begin{tabular}{l} 
Jawaban \\
\cline { 2 - 3 }
\end{tabular}} & \multicolumn{2}{c}{ Komponen Argumentasi } \\
\cline { 2 - 3 } & $\begin{array}{c}\text { Claims (C) } \\
\text { Rebuttals } \\
(\boldsymbol{R})\end{array}$ & $\begin{array}{c}\text { Dasar : } \\
\text { Data (D) } \\
\text { Warrant }(\mathbf{W}) \\
\text { Backing (B) }\end{array}$ \\
\hline a. Tepat & Tepat & $\begin{array}{l}\text { Membahayakan } \\
\text { kesehatan (D), } \\
\text { b. Akan }\end{array}$ \\
membahayakan & & Menjadi sumber \\
kesehatan dan & & penyakit (W), \\
menjadi sumber & & Sampah plastik \\
penyakit karena & & sulit terurai (B) \\
sampah plastik & & \\
sulit terurai & & \\
\hline
\end{tabular}

Permasalahan yang disajikan berjumlah 4 buah terkait dengan pencemaran tanah, air, udara, dan solusi dari pencemaran. Permasalahan-permasalahan yang disajikan tidak terlepas dari tema plastik. Berdasarkan hasil pengelompokkan komponen argumentasi dari 4 permasalahan yang disajikan, siswa masih sulit menyajikan warrant dan backing. Hasil lengkap dapat dilihat pada gambar 2.

Pada permasalahan tentang pencemaran tanah, sebagian besar siswa tidak menuliskan 
warrant dan backing. Berbeda dengan permasalahan kedua tentang pencemaran air. Pada permasalahan pencemaran air sebagian besar siswa menyajikan warrant dan backing yang tidak memiliki keterkaitan dengan data dan claims atau rebuttals.

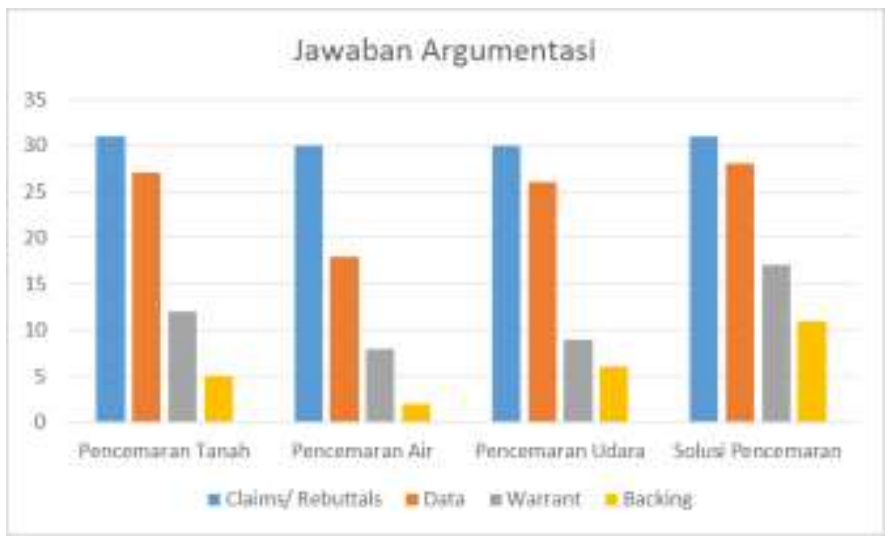

Gambar 2. Analisis Argumentasi dalam Isu Sosiosaintifik

Hasil ini sama dengan penelitian lainnya, bahwa sebagian besar siswa mampu membuat claims atau rebuttals tanpa disertai alasan (data, warrant, dan backing) yang jelas (Erduran et al., 2004; Jimenez-Aleixandre et al., 2000; Kelly et al., 1998; Resnick et al., 1993). Sadler (2004) mengungkapkan bahwa alasan (data, warrant, dan backing) yang dikemukakan oleh siswa pada argumen dalam isu sosiosaintifik dipengaruhi oleh pemahaman konsep siswa itu sendiri. Semakin siswa memahami konsep, maka dapat memberikan argumen yang lebih lengkap dan utuh.

Hasil penelitian ini memberikan gambaran bahwa argumentasi melalui tulisan memiliki tantangan untuk dikembangkan seperti yang dikemukakan oleh Rivard \& Straw (2000) dan Wallace et al. (2004) yang menyatakan bahwa argumentasi melalui tulisan memiliki keunikan tersendiri dibandingkan argumentasi melalui lisan.

\section{Simpulan}

Kualitas argumentasi dalam isu sosiosaintifik siswa SMP masih rendah dikarenakan siswa mampu membuat claims dan rebuttals tetapi sulit membuat alasan (data, warrant, dan backing). Kesulitan membuat alasan didasarkan kepada pemahaman konsep siswa itu sendiri.

\section{Referensi}

Erduran, S., Simon, S., \& Osborne, J. (2004). TAPping into Argumentation: Developments in The Application of Toulmin's Argument Pattern for Studying Science Discourse. Science Education, 88, 915-933.

Gayford, C. (2002). Controversial Environmental Issues:A Case Study for Professional Development of Science Teachers. International Journal of Science Education, 24 (11), 1191-1200.

Hall, D. (2011). Debate: Innovative Teaching to Enhance Critical Thinking and Communication Skills in Healthcare Professionals. The Internet Journal of Allied Health Science and Practice 9(3) Article 7

Inch, E. S. (2006). Critical Thinking and Communication: The use of Reason in Argument. USA: Pearson

Jimenez-Aleixandre, M. P., Rodrigues, A. B., \& Duschl, R. A. (2000). "Doing the lesson" or "Doing science": Argument in High School Genetics. Science Education, 84(6), 757792.

Kelly, G. J., Druker, S., \& Chen, C. (1998). Students' reasoning about Electricity: Combining Performance Assessment with Argumentation Analysis. International Journal of Science Education, 20(7), 849871.

Kelly, G. J., \& Takao, A. (2002) Epistemic Levels in Argument: An Analiysis of University oceanography students' use of evidence in writing. Science Education, 86(3), 314-342.

Kolsto, S. D. (2001). Scientific Literacy for Citizenship: Tools for Dealing with The Science Dimension of Controversial Socioscientific Issues. Science Education, $85,291-310$ 
Lang, M. \& Olson, J. (2000). Integrated Science Teaching as a Challenge for Teachers to Develop New Conceptual Structures. Research in Science Education, 30 (2), 213-224.

Lawson, A. (2003). The Nature and Development of Hypothetico-Deductive Argumentation with Implication for Science Learning. International Journal of Science Education, 25(11), 1378-1408.

Makhene, A. (2017), Argumentation: A Methodology to Facilitate Critical Thinking International Journal of Nursing Education Scholarship

Osborne, J. (2010). Arguing to Learn in Science: The Role of Collaborative, Critical Discourse. Washington, D.C.: American Association for the Advancement of Science.

Partnership for 21st Century Learning. (2015). P21 Framework Definition. Los Angeles: The Partnership for 21st Century Learning

Peraturan Menteri Pendidikan dan Kebudayaan Nomor 21 Tahun 2016 tentang Standar Isi Kurikulum 2013 Revisi untuk Satuan Pendidikan Dasar dan Menengah. 2016. Jakarta.

Resnick, L. B., Salmon, M., Zeitz, C. M., Wathen, S. H., \& Hollowchack, M. (1993). Reasoning in Cnversation. Cognition \& Instruction., 11(3\&4), 347-364

Rivard, L. P., \& Straw, S. B. (2000). The Effect of Talk and Writing on Learning Science: An Exploratory Study. Science Edication, 84, 566-593

Sadler, T. D. (2004). Informal Reasoning Regarding Socioscientific Issues: A Critical Review of Research. Journal of Research in Science and Teaching, 41 (5), 513-536

Sadler, T. D. \& Zeidler, D. L. (2004). The Morality of Socioscientific Issued: Construal and Resolution of Genetic Engineering Dilemmas. Science Education, 88, 4-27
Sadler, T.D., Chambers, F. W., \& Zeidler, D. L. (2004). Student Conceptualisation of The Nature of Science in Respone to a Sociosaintific Issues. International Journal of Science Education. 26 (4), 387-410

Sadler, T. D. \& Donnelly, L. A. (2006). Socioscientific Argumentation. The Effects of Content Knowledge and Morality. International journal of Science Education, 28 (12), 1463-1488

Sampson, V. \& Clark, D. (2006). Assessment of Argument in Science Education: A Critical Review of the Literature. In Proceedings of international Conference of the Learning Sciences 2006, Bloomington, IN. (pp. 655-661)

Sandoval, W. (2003). Conceptual and Epistemic Aspects of Students' scientific Explanation. Journal of the Learning Sciences, 12(1), 5-51.

Sandoval, W. \& Millwood, K. (2005). The Quality of Students use of Evidence in Written Scientific Explanation. Cognition \& Instruction, 23(1), 23-55.

Sanders, J.A., Wiseman, R.L., and Gass, R.H. (1994). Does teaching argumentation facilitate critical thinking? Communication Reports 7:1 p 27-35.

Takao, A., \& Kelly, G. (2003). Assessment of Evidence in University Students' scientific Writing. Science \& Education, 12(4), 341363.

Wallace, C. S., Hand, B., \& Prain, V. (2004). Writing and Learning in The Science Classroom. Dordecht, The Netherlands: Kluwer Academic.

Zohar A., \& Nemet, F. (2002). Fostering Students' Knowledge and Argumentation Skills Trough Dillemas in Human genetics. Journal of Research in Science Teaching, 39(1), 35-62. 